Western University Scholarship@Western

Electrical and Computer Engineering Publications Electrical and Computer Engineering Department

$1-2012$

\title{
Evolution of Software Engineers' Personality Profile
}

\section{Daniel Varona}

University of Informatics Sciences, dvarona@uci.cu

Luiz Fernando Capretz

University of Western Ontario, lcapretz@uwo.ca

ArifRaza

National University of Science and Technology - Pakistan, arif_raza@mcs.edu.pk

Follow this and additional works at: https://ir.lib.uwo.ca/electricalpub

Part of the Other Computer Sciences Commons, and the Software Engineering Commons

\section{Citation of this paper:}

@article $\{$ DBLP:journals/sigsoft/VaronaCPR12, author $=\{$ Daniel Varona and Luiz Fernando Capretz and Yadenis $\operatorname{Pi}\{\backslash \sim \mathrm{n}\}$ ero and Arif Raza $\}$, title $=\{$ Evolution of software engineers' personality profile $\}$, journal $=\{$ ACM SIGSOFT Software Engineering Notes $\}$, volume $=\{37\}$, number $=\{1\}$, year $=\{2012\}$, pages $=\{1-5\}$, ee $=\{$ http: $/ /$ doi.acm.org $/ 10.1145 / 2088883.2088901\}$, bibsource $=$ \{DBLP, http://dblp.uni-trier.de\} $\}$ 


\section{Evolution of Software Engineers' Personality Profile}

\author{
Daniel Varona \\ University of Informatics \\ Sciences \\ Havana, Cuba \\ dvarona@uci.cu
}

\author{
Luiz Fernando Capretz \\ University of Western \\ Ontario \\ London, Canada N6A 5B9 \\ Icapretz@uwo.ca
}

\author{
Yadenis Piñero \\ University of Informatics \\ Sciences \\ Havana, Cuba \\ yadenis@uci.cu
}

\author{
Arif Raza \\ University of Sciences \\ and Technology \\ Islamabad, Pakistan \\ arif_raza@mcs.edu.pk
}

\begin{abstract}
The Myers-Briggs Type Indicator (MBTI) has been applied to several studies that explore various dimensions of human factors in software engineering. Accordingly, this work reviews the results of these studies to explore existing trends. In order to attain a greater understanding of human resources in the software industry, we have reviewed sixteen studies that had been performed between 1985 and 2011. This review concludes that the changes in the complexity of software processes and products have created new roles and demanded new skills for software engineers.
\end{abstract}

\section{Categories and Subject Descriptors}

D.2.[Software Engineering]: Software Engineer and Human Factors.

\section{General Terms}

Human Factors.

\section{Keywords}

MBTI, Personality Types, Software Engineering, Human Factors.

\section{INTRODUCTION}

Since there are various dimensions of human aspects of software engineering, studies have been performed from different perspectives to account for such a variety of dimensions. These perspectives include human factors in different phases of the software life cycle, the effect of team work in software development, or the correspondence between personality profiles and tasks. In this review, we will attempt to classify the types of research that have already been conducted in these areas and ascertain potential gaps in the literature.

The evolution of the software industry necessitates the meticulous study of personality trends in the profession. Specifically, human factors should be considered because software engineers could benefit from a greater awareness of themselves and others in order to develop their "soft skills," which can subsequently influence their work. Accordingly, studies related to human resource management in software engineering have increased since the 1980's, thus demonstrating the motivation to understand the personality traits and social factors that influence software development.

Myers-Briggs Type Indicator (MBTI) [13] is the most commonly used models in empirical studies of human aspects of software engineer. Many studies have utilized the MBTI scales to learn the personality types and traits of software engineers and information technology specialists. A person's inclination towards a specific way of acquiring information or making decisions influences their preference for certain tasks and jobs. This trend is represented in the personality type distribution tables, which characterize the personality profile of software engineers. However, recent studies have revealed new patterns that are related to personality type distribution of software engineers. Therefore, this investigation will review the last three decades of MTBI studies to expose trends in software developers' personality profiles.

\section{LITERATURE REVIEW}

The Myers-Briggs Type Indicator, based on Jung's type theory, defines four pairs of opposing personality types for a total of eight traits.
Although individuals may use all eight characteristics in each of the four pairs, most people tend to prefer one trait in each pair. The four pairs and their corresponding traits are explained below:

a) Extroverts (E) are individuals whose attention is focused on objects and people, and they prefer to communicate and process information verbally. Alternatively, Introverts (I) concentrate on the inner world of ideas, emotions and impressions, and consequently, they tend to process information inside of their heads.

b) Sensing (S) individuals are attuned to the practical, hands-on, common-sense view of events. On the other hand, Intuitive $(\mathrm{N})$ people pay attention to complex interactions patterns, theoretical implications and new possibilities.

c) Feeling $(\mathrm{F})$ individuals consider human factors and make judgments based on their value. Conversely, Thinking (T) people draw conclusions or make judgments dispassionately and analytically in addition to seeking an objective standard of truth.

d) Perceiving $(\mathrm{P})$ individuals demonstrate flexibility and spontaneity, while Judging $(\mathrm{J})$ people tend to seek closure, structure and organization.

Based on these four pairs of opposing traits, there are 16 possible configurations of personality types. For example, if the MBTI results show that a person is ISTP, then the appropriate terminology suggests that the person prefers ISTP.

Many studies that refer to the MBTI personality type distribution include participants such as the general population, engineers, students and software engineers. These works have demonstrated that the subjects possess specific personality traits according to their respective fields and occupations.

Comparative analysis examined the combined data from MBTI assessment concluded that while thinkers (T) and judgers (J) are particularly attracted to software engineering, feelers $(\mathrm{F})$ and perceivers (P) are less inclined towards this field. These studies also emphasize that the common personality preferences of the general US population are not reflected within the discipline of software engineering.

Furthermore, it was known, with regard to programming tasks, that the three most common personality types, in order of preference, were ISTJ, INTJ and ENTP. Moreover, studies also concluded that thinking and judging were very common preferences. In addition other studies marked INTP as part of those over-represented. On the other hand, ESFJ, and ISFP were particularly under-represented.

Concerning systems analysts, the most frequent personality types were ISTJ and ESTJ. Although results indicated greater proportions of introverts (I), there was also a clear bias towards the sensing (S), thinking (T), and judging (J) types; as well as the under-representation of 'Fs' and 'Ns' in the engineering personality profile [2]. In addition, most of these studies depicted a predominance of ISTJ, INTJ and ESTJ personality types, whereas the ENFJ and INFJ types were underrepresented.

Although there has been a clear pattern in the personality types of software engineers, the evolution of their profiles has not yet been investigated. Accordingly, this research aims to address this issue and 
present an in-depth analysis of differences in personality types over time.

\section{RESEARCH METHODOLOGY}

The goal of this research is to delve into the studies of software engineering personality types using the MBTI instrument. We found 16 studies that presented a detailed MBTI personality type distribution data and conclusive results related to software engineers and their personality types. These 16 studies have been published within the last 30 years, between 1985 and 2011, and they involved 3449 software engineers in different parts of the world. The summary from these studies is presented below in Table 1 and Table 2.

Nevertheless the information shown in this study has intrinsic limitations on how the original data collection processes were carried out, we were not much explicit on detailing how the MBTI assessments were administered. Also there were different sample sizes, and neither proportion between genders nor ages were always revealed. This means that the data does not describes homogeneous groups but still can be considered as valid. Comparisons between studies were not conducted, they were just used to identify personality trend through the years.

Table 1. Research results for Extrovert personality type

\begin{tabular}{|c|c|c|c|c|c|c|c|c|c|}
\hline Study & Size & ENF & ENFP & ENTJ & ENTP & ESFJ & ESFP & ESTJ & ESTP \\
\hline $\begin{array}{c}1985 \mathrm{a} \\
{[10]}\end{array}$ & 1229 & $2.4 \%$ & $3.4 \%$ & $8.4 \%$ & $5.6 \%$ & $1.0 \%$ & $0.7 \%$ & $9.3 \%$ & $2.1 \%$ \\
\hline $\begin{array}{c}1988 \\
{[3]}\end{array}$ & 47 & $2.1 \%$ & $4.3 \%$ & $4.3 \%$ & $0.0 \%$ & $0.0 \%$ & $6.4 \%$ & $6.4 \%$ & $2.1 \%$ \\
\hline $\begin{array}{c}1988 \mathrm{a} \\
{[19]}\end{array}$ & 153 & $1.3 \%$ & $5.2 \%$ & $8.5 \%$ & $5.9 \%$ & $2.6 \%$ & $0.7 \%$ & $27.5 \%$ & $3.9 \%$ \\
\hline $\begin{array}{c}1989 \\
{[15]}\end{array}$ & 37 & $0.0 \%$ & $0.0 \%$ & $2.7 \%$ & $2.7 \%$ & $2.7 \%$ & $0.0 \%$ & $29.7 \%$ & $2.7 \%$ \\
\hline $\begin{array}{c}1990 \\
{[17]}\end{array}$ & 656 & $3.8 \%$ & $1.5 \%$ & $6.0 \%$ & $1.7 \%$ & $4.9 \%$ & $1.5 \%$ & $25 \%$ & $0.6 \%$ \\
\hline $\begin{array}{c}1997 \mathrm{a} \\
{[6]}\end{array}$ & 22 & $9.09 \%$ & $0.0 \%$ & $18.2 \%$ & $0.0 \%$ & $9.09 \%$ & $0.0 \%$ & $0.0 \%$ & $0.0 \%$ \\
\hline $\begin{array}{c}1998 \mathrm{a} \\
{[16]}\end{array}$ & 38 & $13.2 \%$ & $7.89 \%$ & $2.63 \%$ & $15.8 \%$ & $2.63 \%$ & 2.63 & $10.5 \%$ & $5.2 \%$ \\
\hline $\begin{array}{c}2002 \mathrm{a} \\
{[11]}\end{array}$ & 419 & $3.34 \%$ & $2.63 \%$ & $5.01 \%$ & $8.35 \%$ & $3.58 \%$ & 0.95 & $17.4 \%$ & $5.49 \%$ \\
\hline $\begin{array}{c}2003 \\
{[4]}\end{array}$ & 100 & $1.0 \%$ & $3.0 \%$ & $4.0 \%$ & $7.0 \%$ & $4.00 \%$ & $1.0 \%$ & $15.0 \%$ & $8.0 \%$ \\
\hline $\begin{array}{c}2004 \\
{[12]}\end{array}$ & 33 & $0.0 \%$ & $0.0 \%$ & $6.06 \%$ & $6.06 \%$ & $9.09 \%$ & $0.0 \%$ & $18.2 \%$ & $0.0 \%$ \\
\hline $\begin{array}{c}2004 \mathrm{~b} \\
{[8]}\end{array}$ & 19 & $42.1 \%$ & $5.26 \%$ & $5.26 \%$ & $5.26 \%$ & $0.0 \%$ & $0.0 \%$ & $5.26 \%$ & $0.0 \%$ \\
\hline $\begin{array}{c}2004 \mathrm{c} \\
{[7]}\end{array}$ & 66 & $0.0 \%$ & $1.50 \%$ & $3.0 \%$ & $4.5 \%$ & $3.0 \%$ & $0.0 \%$ & $18.0 \%$ & $1.5 \%$ \\
\hline $\begin{array}{c}2006 \mathrm{~b} \\
{[9]}\end{array}$ & 128 & $2.3 \%$ & $5.50 \%$ & $2.3 \%$ & $3.1 \%$ & $5.5 \%$ & $5.5 \%$ & $14.8 \%$ & $5.5 \%$ \\
\hline $\begin{array}{c}2008 \mathrm{~b} \\
{[5]}\end{array}$ & 68 & $1.47 \%$ & $2.94 \%$ & $4.41 \%$ & $7.35 \%$ & $2.94 \%$ & $1.5 \%$ & $11.7 \%$ & $11.7 \%$ \\
\hline $\begin{array}{c}2010 \\
{[1]}\end{array}$ & 235 & $2.35 \%$ & $2.35 \%$ & $17.6 \%$ & $2.35 \%$ & $2.35 \%$ & $3.5 \%$ & $2.35 \%$ & $3.53 \%$ \\
\hline $2010 \mathrm{a}$ & 103 & $2.91 \%$ & $3.88 \%$ & $6.8 \%$ & $1.94 \%$ & $1.94 \%$ & $5.8 \%$ & $26.2 \%$ & $13.6 \%$ \\
\hline
\end{tabular}

Table 2. Research results for Introvert personality type

\begin{tabular}{|c|c|c|c|c|c|c|c|c|c|}
\hline Study & Size & INFJ & INFP & INTJ & INTP & ISFJ & ISFP & ISTJ & ISTP \\
\hline $\begin{array}{c}1985 \mathrm{a} \\
{[10]}\end{array}$ & 1229 & $2.7 \%$ & $3.6 \%$ & $16 \%$ & $12 \%$ & $3.9 \%$ & $1.5 \%$ & $22.6 \%$ & $5.2 \%$ \\
\hline $\begin{array}{c}1988 \\
{[3]}\end{array}$ & 47 & $8.5 \%$ & $6.4 \%$ & $13 \%$ & $14 \%$ & $4.3 \%$ & $0.0 \%$ & $19.2 \%$ & $8.5 \%$ \\
\hline $\begin{array}{c}1988 \mathrm{a} \\
{[19]}\end{array}$ & 153 & $0.0 \%$ & $0.7 \%$ & $6.5 \%$ & $4.6 \%$ & $3.3 \%$ & $3.9 \%$ & $19.6 \%$ & $5.9 \%$ \\
\hline $\begin{array}{c}1989 \\
{[15]}\end{array}$ & 37 & $0.0 \%$ & $0.0 \%$ & $8.1 \%$ & $5.4 \%$ & $8.1 \%$ & $0.0 \%$ & $35.1 \%$ & $2.7 \%$ \\
\hline $\begin{array}{c}1990 \\
{[17]}\end{array}$ & 656 & $2.9 \%$ & $0.5 \%$ & $6.5 \%$ & $0.6 \%$ & $5.2 \%$ & $0.60 \%$ & $38.0 \%$ & $0.60 \%$ \\
\hline $\begin{array}{c}1997 \mathrm{a} \\
{[6]}\end{array}$ & 22 & $4.55 \%$ & $4.55 \%$ & $23 \%$ & $0.0 \%$ & $4.5 \%$ & $4.5 \%$ & $18.2 \%$ & $4.55 \%$ \\
\hline $\begin{array}{c}1998 \mathrm{a} \\
{[16]}\end{array}$ & 38 & $0.0 \%$ & $7.89 \%$ & $11 \%$ & $5.3 \%$ & $2.6 \%$ & $0.0 \%$ & $5.26 \%$ & $7.89 \%$ \\
\hline $\begin{array}{c}2002 \mathrm{a} \\
{[11]}\end{array}$ & 419 & $2.15 \%$ & $2.15 \%$ & $8.1 \%$ & $6.4 \%$ & $5.5 \%$ & $0.95 \%$ & $21.7 \%$ & $6.21 \%$ \\
\hline $\begin{array}{c}2003 \\
{[4]}\end{array}$ & 100 & $0.0 \%$ & $2.0 \%$ & $7.0 \%$ & $8.0 \%$ & $3.0 \%$ & $5.0 \%$ & $24.0 \%$ & $8.0 \%$ \\
\hline $\begin{array}{c}2004 \\
{[12]}\end{array}$ & 33 & $3.03 \%$ & $3.03 \%$ & $6.1 \%$ & $3.0 \%$ & $15 \%$ & $3.03 \%$ & $21.2 \%$ & $6.06 \%$ \\
\hline $\begin{array}{c}2004 \mathrm{~b} \\
{[8]}\end{array}$ & 19 & $15.8 \%$ & $0.0 \%$ & $0.0 \%$ & $16 \%$ & $5.3 \%$ & $0.0 \%$ & $0.0 \%$ & $0.0 \%$ \\
\hline $\begin{array}{c}2004 \mathrm{c} \\
{[7]}\end{array}$ & 66 & $0.0 \%$ & $4.50 \%$ & $12 \%$ & $1.5 \%$ & $4.5 \%$ & $0.0 \%$ & $39.0 \%$ & $6.0 \%$ \\
\hline $\begin{array}{c}2006 \mathrm{~b} \\
{[9]}\end{array}$ & 128 & $0.80 \%$ & $7.0 \%$ & $3.9 \%$ & $7.0 \%$ & $5.5 \%$ & $6.30 \%$ & $21.1 \%$ & $3.10 \%$ \\
\hline $\begin{array}{c}2008 \mathrm{~b} \\
{[5]}\end{array}$ & 68 & $1.47 \%$ & $2.94 \%$ & $7.4 \%$ & $13 \%$ & $2.9 \%$ & $4.41 \%$ & $19 \%$ & $4.41 \%$ \\
\hline $\begin{array}{c}2010 \\
{[1]}\end{array}$ & 235 & $2.35 \%$ & $4.71 \%$ & $7.1 \%$ & $4.7 \%$ & $9.4 \%$ & $3.53 \%$ & $28.2 \%$ & $3.53 \%$ \\
\hline $2010 \mathrm{a}$ \\
\hline 18$]$
\end{tabular}

\section{RESULTS}

The results of different studies that involve Extrovert and Introvert personality types are presented above in Table 1 and Table 2 respectively.

The results depicted in both tables can be more clearly understood in a graphic form, where the percentage variation for each personality type is displayed. Figure 1 shows the results for the MTBI personality types for all 16 sources. The replication of values for the majority of types is evident. Furthermore, the values of certain personality types, such as ESTJ, INTJ, INTP, and ISTJ, indicate a higher variation of the percentage levels of the less stable personality types. Similar trend can be found in the data gathered and published by Rien et. al [14]. 


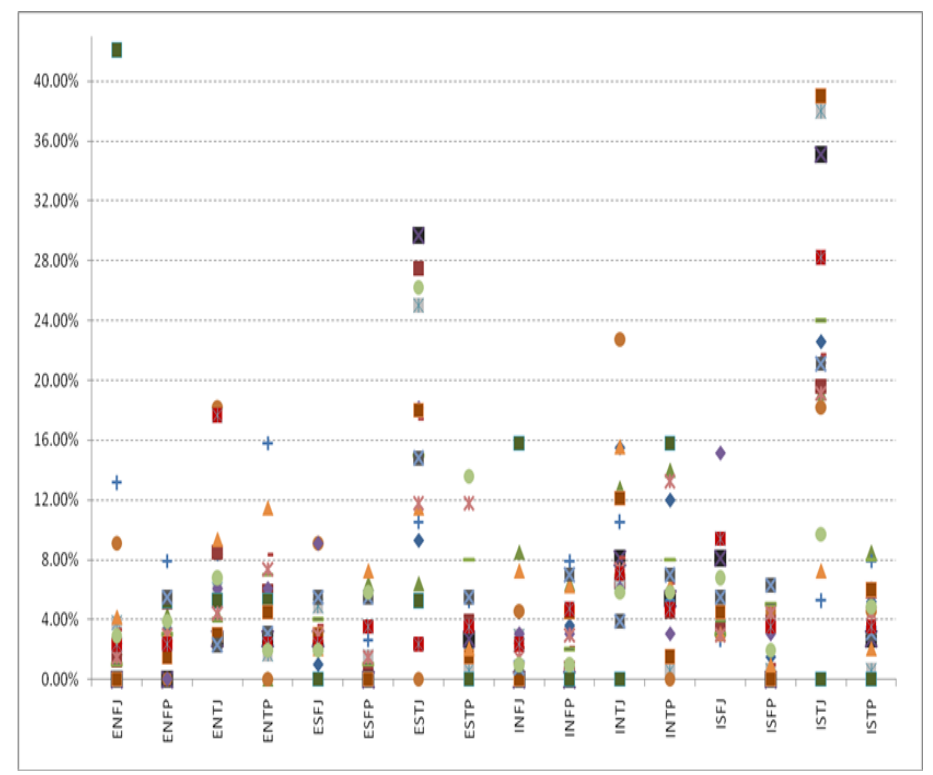

Figure 1. MBTI results

The percentage of personality types varies throughout the three decades of study, especially the INTJ, ISTJ, and ESTP types, as demonstrated in Figures 2 and 3. In Figure 2, the INTJs and ISTJs present a decreasing slope of approximately 10 percentile points.

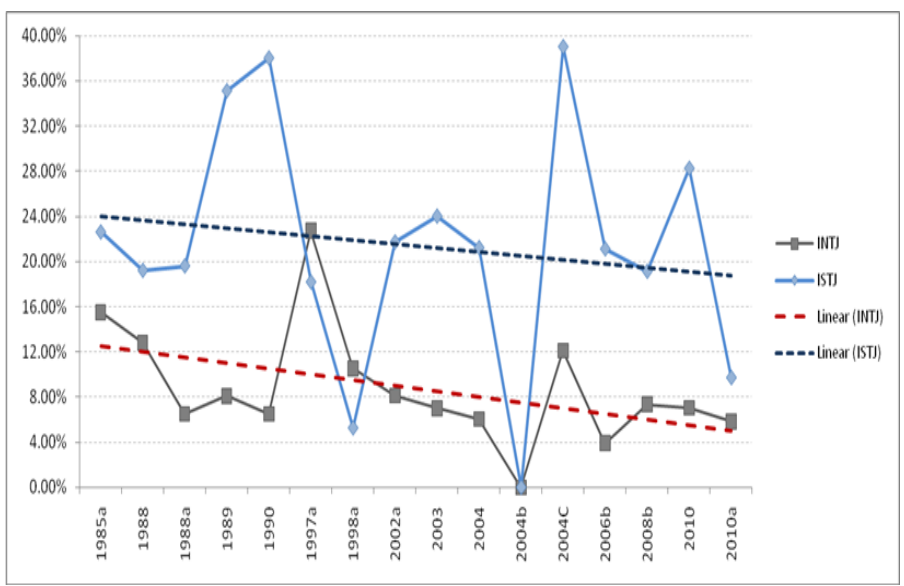

Figure 2. Trend analysis for INTJ and ISTJ personality types

Contrastingly, ESTP shows an increasing slope of approximately 10 percentile points, as shown in Figure 3. These values, however, are still lower than those of the INTJ and ISTJ personality types.

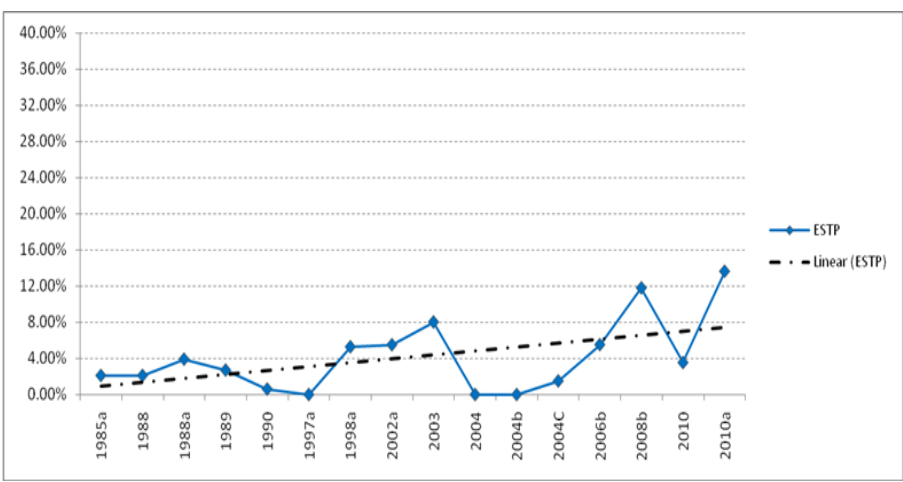

Figure 3. Trend analysis for ESTP personality type
Figure 4 presents an analysis of the Extrovert and Introvert MTBI dimension, where the proportion of extroverts has increased over the years while introverts have decreased in the same time period of time.

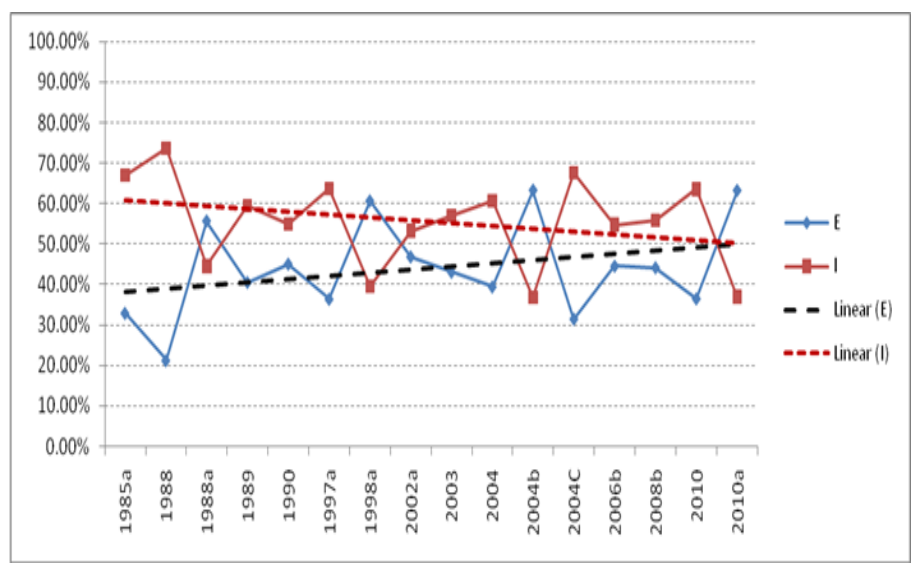

Figure 4. Trend analysis for Extrovert-Introvert dichotomies

Historically, the proportion of thinkers has outnumbered that of feelers, who have demonstrated lower percentages in research results [14]. However, over the past thirty years, there has been a remarkable increase in the percentage of feelers and a corresponding decrease in the percentage of thinkers, which is evidenced in Figure 5.

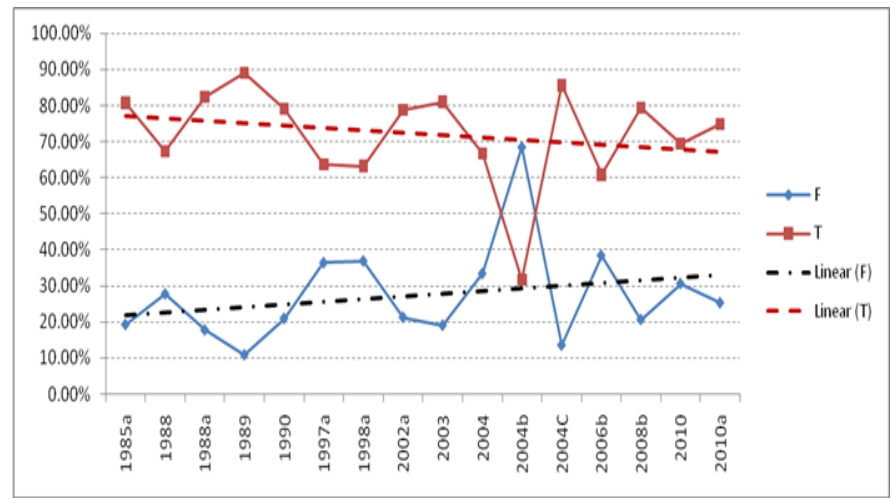

Figure 5. Trend analysis for Thinking-Feeling dichotomies

As presented in Figure 6, judging types have become increasingly prominent, while the proportion of perceiving types has decreased.

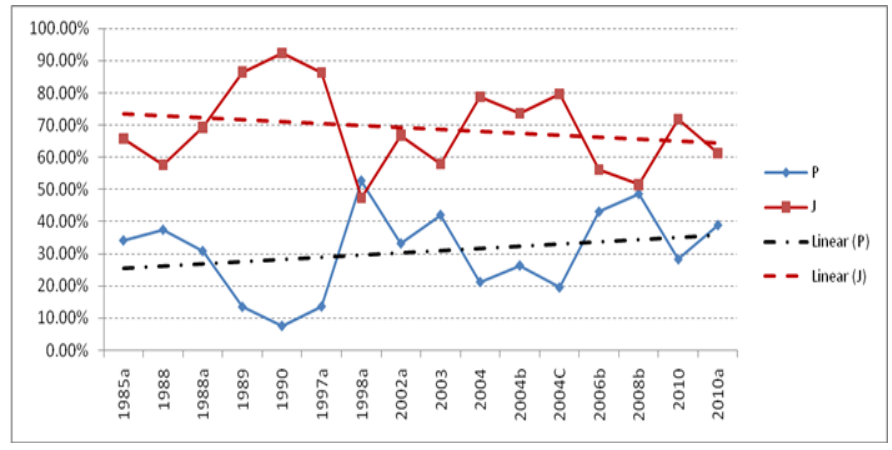

Figure 6. Trend analysis for Judging-Perceiving dichotomies

Finally, while the other three pairs have experienced an evolving relationship, there have been no significant changes in the SensingIntuitive dimension during the time period between 1985 and 2010. 


\section{DISCUSSION}

The historical analysis of software engineering personality types demonstrates a change in the proportions of software engineers possessing a specific personality type. Although the percentage of extroverts has traditionally been lower than that of introverts, there is a current tendency towards reversing this trend. This altered relationship could be associated with the increasingly diverse activities in the software industry over the last thirty years and the ubiquity of software.

The increasing complexity of software projects requires people with stronger communications and teamwork skills. In small projects, agile methodologies are frequently used for software development, where client-developer interaction is necessary. In addition, tools for automatic code generation diminish programming efforts, which consequently decrease the traditional demand for introverted programmers [1].

In comparison to perceiving individuals, judging people are more interested in software engineering jobs [14]. This pattern may be influenced by the fact that the dominant tasks in software development include planning, management and analysis. The greater proportion of judging individuals could indicate the presence of more organized development processes in the software industry.

In the Thinking-Feeling dimension, thinkers represent the majority of reported results [14]. However, the teamwork and communication required in software projects could be attracting more feelers to the software engineering profession. It is likely that many feeling individuals may find their niche in less technical and more peopleoriented aspects of software development. For example, feelers may experience more contentment as software engineers who have direct user contact than those who hack software code [4].

\section{CONCLUSION}

The underlying contextual factors for each of these studies might be different. The only criterion for inclusion is that they all evaluated personality types using the MBTI instrument. Although the trend showed is of interest, it points to a more detailed analysis of the different studies before a final conclusion can be drawn. In particular, much more analysis is needed on the purpose of these primary studies, as well as information on the pool of participants in each study.

The discrepancies presented in those studies suggest that there is still more understanding to be gained about personality in software engineering, as we do not by any means know the exact breakdown of types among software professionals. Nonetheless we can confirm that certain traits are prevalent in the software industry, and that software engineering attracts people of all psychological types [20].

The representation of INTJs and ISTJs has decreased by nearly ten percentile points over the last thirty years, while the prominence of ESTPs has increased by the same amount over the same time period. The ESTJ, INTJ, INTP, and ISTJ types have been less stable in their representation throughout three decades of studies.

Complexity changes in software process and products have demanded new roles and skills for software developers. Hence, the changing proportions in the personality types of software engineers seem to be a natural evolution in the field.

Finally, the increasing variety of personality types poses an advantage for the area of software engineering. Accordingly, the new personality profiles in this field should enable the software industry to achieve higher levels of efficiency, productivity, and quality. This investigation, however, did not touch upon the effect of personality types on team cohesion and performance.

\section{REFERENCES}

[1] Ahmed, F., Campbell, P., Jaffar, A., Alkobaisi, S. \& Campbell, J. 2010. Learning \& Personality Types: A Case Study of a Software
Design Course. Journal of Information Technology Education: Innovations in Practice, 9, 237-252.

[2] Bishop-Clark, C. \& Wheeler, D. D. 1994. The Myers Briggs Personality Type and its Relationship to Computer Programming. Journal of Research on Computing, 26, 3, 358-370.

[3] Buie, E. A. 1988. Psychological Type and Job Satisfaction in Scientific Computer Professionals. Journal of Psychological Types 15, 50-53.

[4] Capretz, L. F. 2003. Personality Types in Software Engineering. International Journal of Human-Computer Studies, 58, 2, 207214.

[5] Capretz, L. F. 2008. Psychological Types of Brazilian Software Engineering Students. Journal of Psychological Types, 68, 5, 37 42.

[6] John, H. B. \& Frederic, J. H. 1997. The Effect of Personality Type on Team Performance. Journal of Management Development, 16, 5, 337-353.

[7] Kaluzniacky, E. 2004. Managing Psychological Factors in Information Systems Work, London, Information Science Publishing.

[8] Karn, J. S. \& Cowling, A. J. 2004. A Study into the Effect of Disruptions on the Performance of Software Engineering Teams. University of Sheffield, Sheffield, U.K.

[9] Kyungsub, S. C. 2006. An Analysis of Computing Major Students' Myers-Briggs Type Indicator Distribution. The Information Systems Education Conference, Chicago. AITP Foundation for Information Technology Education (FITE).

[10] Lyons, M. 1985. The DP Psyche. Datamation, 31, 16, 103-105.

[11] Mackness, A. M., Poore, E. T. \& Tucker, J. 2002. Information Technology Team Dynamics - What it Means to the IT industry. $14^{\text {th }}$ Annual Software Technology Conference, Salt Lake City, UT, US. Department of Defense.

[12] Miller, J. \& Zhichao, Y. 2004. A Cognitive-Based Mechanism for Constructing Software Inspection Teams. IEEE Transactions on Software Engineering, 30, 11, 811-825.

[13] Myers, I. B., Mccaulley, M. H., Quenk, N. L. \& Hammer, A. L. 1998. MBTI Manual. A Guide to the Development and Use of the Myers-Briggs Type Indicator, Palo Alto, CA, Consulting Psychologists Press.

[14] Sach, R., Petre, M. \& Sharp, H. 2010. The Use of MBTI in Software Engineering. 22nd Annual Psychology of Programming Interest Group, Sep. 2010 Madrid. Universidad Carlos III.

[15] Smith, D. C. 1989. The Personality of the Systems Analyst: An Investigation. ACM SIGCPR Computer Personnel, 12, 2, 12-14.

[16] Teague, J., 1998. Personality Type, Career Preference and Implications for Computer Science Recruitment and Teaching. Proceedings of the 3rd Australasian conference on Computer science education, 1998 New York, NY. ACM, 155-163.

[17] Thomsett, R. 1990. People \& Project Management, Englewood Cliffs, NJ, Prentice-Hall.

[18] Varona, D., Capretz, L. F. 2011. Personality Types of Cuban Software Engineers. Global Journal of Engineering Education, WIETE, 13, 2, 77-81.

[19] Westbrook, P. 1988. Frequencies of MBTI Types Among Computer Technicians. Journal of Psychological Types, 15, 49, 111. 
[20] Capretz, L.F. and Ahmed F. 2010. Why Do We Need Personality Diveristy in Software Engineering. ACM SIGSOFT Software Engineering Notes, 35, 2, 1-11.

\section{AUTHORS' BIOSKETCH}

Daniel Varona received his Engineering in Informatics Sciences degree from the University of Informatics Sciences, Havana, Cuba (2008). His current research interests include software engineering (SE), human factors in SE, software project management, adaption of software development methodologies to specific environments and social impact of software products. He is currently a faculty member at the University of Informatics Sciences, Cuba and can be reached at dvarona@uci.cu.

Luiz Fernando Capretz has over 30 years of international experience in the software engineering field as a practitioner, manager and educator. Having worked in Brazil, Argentina, U.K., Japan, Italy and the UAE, he is currently Assistant Dean (IT and eLearning) at the University of Western Ontario, Canada. He has published over 100 peer-reviewed research papers on software engineering in leading international journals and conference proceedings, and he has co-authored two books in the field. His present research interests include software engineering (SE), human factors in SE, software estimation, technology for teaching, and software engineering education. Dr. Capretz received his Ph.D. in Computing Science from the University of Newcastle (U.K.), his M.Sc. in Applied Computing from the National Institute for Space Research (INPE, Brazil), and his B.Sc. in Computer Science from State University of Campinas (UNICAMP, Brazil). He is an IEEE senior member, ACM member, MBTI certified practitioner, Professional Engineer in Ontario (Canada), and can be contacted at lcapretz@uwo.ca.

Yadenis Piñero received her M.Sc. (2008) in Informatics Project Management from the University of Informatics Sciences, Havana, Cuba; and her Informatics Engineering degree from Higher Polytechnic Institute, Havana, Cuba. Having worked in Mexico, Venezuela, Canada, and Cuba, he is currently the Head of Software Development Projects at the University of Informatics Sciences, Havana, Cuba. She has authored and co-authored several research articles in conference proceedings in the area of software engineering. Her current research interests include empirical investigation regarding human factors in informatics project management and assessment of human resources competencies. She is currently a professor at the University of Informatics Sciences, Cuba and can be reached at yadenis@uci.cu.

Arif Raza received his M.Sc. (1994) in Computing Science from University of London (U.K.), and $\mathrm{PhD}$ (2011) in Software Engineering from the University of Western Ontario (Canada). During his professional career, he has been actively involved in teaching and research. Dr. Raza has authored and co-authored several research articles in peer reviewed journals and conference proceedings. His current research interests include usability issues in open source software (OSS), human computer interaction, human factors and empirical studies in software engineering. He is presently serving as Assistant Professor at University of Sciences and Technology, Pakistan and can be reached at arif_raza@mcs.edu.pk. 